\title{
Outcome of domiciliary nasal intermittent positive pressure ventilation in restrictive and obstructive disorders
}

\author{
A K Simonds, $M$ W Elliott*
}

\begin{abstract}
Background - Nasal intermittent positive pressure ventilation (NIPPV) is a new technique which has rapidly supplanted other non-invasive methods of ventilation over the last 5-10 years. Data on its effectiveness are limited.
\end{abstract}

Methods - The outcome of long term domiciliary NIPPV has been analysed in $\mathbf{1 8 0}$ patients with hypercapnic respiratory failure predominantly due to chest wall restriction, neuromuscular disorders, or chronic obstructive lung disease. One hundred and thirty eight patients were started on NIPPV electively, and 42 following an acute hypercapnic exacerbation. Outcome measures were survival (five year probability of continuing NIPPV), pulmonary function, and health status. A crossover study from negative pressure ventilation to NIPPV was carried out in a subgroup of patients.

Results - Five year actuarial probability of continuing NIPPV for individuals with early onset scoliosis $(n=47)$, previous poliomyelitis ( $n=30$ ), following tuberculous lung disease $(n=20)$, general neuromuscular disorders $(n=29)$, and chronic obstructive pulmonary disease (n = 33) was $79 \%$ (95\% CI 66 to 92), $100 \%$, 94\% (95\% CI 83 to 100), 81\% (95\% CI 61 to 100$), 43 \%(95 \%$ CI 6 to 80$)$, respectively. Most of the patients with bronchiectasis died within two years. One year after starting NIPPV electively the mean (SD) $\mathbf{P a O}_{2}$ compared with the pretreatment value was +1.8 (1.9) kPa, mean $\mathrm{PaCO}_{2}-1.4(1.3)$ $\mathrm{kPa}$ in patients with extrapulmonary restrictive disorders, and $\mathrm{PaO}_{2}+0.8(1 \cdot 0)$ $\mathrm{kPa}, \mathrm{PaCO}_{2}-0.9(0.8) \mathrm{kPa}$ in patients with obstructive lung disease. Arterial blood gas tensions improved in patients transferred from negative pressure ventilation to NIPPV. Health status was ranked highest in patients with early onset scoliosis, previous poliomyelitis, and following tuberculous lung disease. In the group as a whole health perception was comparable to outpatients with other chronic disorders.

Conclusions - The long term outcome of domiciliary NIPPV in patients with chronic respiratory failure due to scoliosis, previous poliomyelitis, and chest wall and pulmonary disease secondary to tuberculosis is encouraging. The results of NIPPV in patients with COPD and pro- gressive neuromuscular disorders show $\stackrel{\mathbb{D}}{\stackrel{2}{2}}$ benefit in some subgroups. The outcome of in end stage bronchiectasis is poor.

(Thorax 1995;50:604-609)

Keywords: NIPPV, domiciliary ventilation, chronic respiratory failure.

Home ventilation is one of the earliest forms of technological support to be applied in the

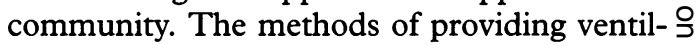
atory assistance for individuals with respiratory $\overrightarrow{ }$ insufficiency have changed over the last $50 \subseteq$ years. ${ }^{1}$ Negative pressure systems (cuirass, pneumojacket, iron lung) were introduced at $\vec{\theta}$ the time of the poliomyelitis epidemics in the of 1940 s and the delivery of ventilation via a tracheostomy has been used since the 1950s. Nasal intermittent positive pressure ventilation (NIPPV) is the most recent advance in the field of non-invasive ventilatory support, entering $\stackrel{\square}{\Omega}$ clinical practice in the mid 1980s. As a new $\overrightarrow{\vec{A}}$ form of therapy, NIPPV has been assessed 3 in respect of its short term effects in acute hypercapnic exacerbations of chronic lung dis-? ease $^{2-5}$ and in patients unable to wean from conventional ventilation. ${ }^{6}$ However, there is $\frac{\text { O }}{7}$ little information on the impact of NIPPV on $x$ survival, ${ }^{7}$ the quality of life, ${ }^{8}$ and functional $\frac{5}{3}$ level in individuals with chronic ventilatory insufficiency.

\section{Methods}

SUBJECTS

Patients were classified by primary diagnosis. $\stackrel{N}{\sim}$ Of 180 patients who were started on NIPPV N at the Royal Brompton Hospital over the period N 1987-92, 47 had early onset idiopathic sco- 0 liosis, 30 had previous poliomyelitis, 20 old tuberculous lung disease with associated chest wall lesions (thoracoplasty, artificial pneumo- $\stackrel{?}{+}$ thorax, phrenic nerve crush), 29 had neuro- 0 muscular disorders (eight muscular dystrophy, eight central hypoventilation, five myopathies, $\cong$ four spina bifida, two polyneuropathies, one $\stackrel{\square}{\Omega}$ spinal muscular atrophy, one motor neurone disease), 33 had chronic obstructive pulmonary 0 disease (COPD), and 13 bronchiectasis. A remaining group comprised eight patients with miscellaneous disorders (three obesity/hypoventilation, two scleroderma, one Proteus syndrome, one osteogenesis imperfecta, one chylothorax). Patient characteristics are given in table 1 .

The indication for domiciliary NIPPV was symptomatic, chronic hypercapnic respiratory 
Table 1 Mean (SD) age, baseline arterial blood gas tensions and spirometric values of 180 patients in study

\begin{tabular}{|c|c|c|c|c|c|}
\hline & Age (years) & $\mathrm{PaO}_{2}(k \mathrm{~Pa})$ & $\mathrm{PaCO}_{2}(k \mathrm{~Pa})$ & $F V C$ (l) & $F E V_{1}(l)$ \\
\hline $\begin{array}{l}\text { Early onset scoliosis }(n=47) \\
\text { Previous polio }(n=30) \\
\text { Previous tuberculosis }(n=20) \\
\text { Neuromuscular disorders }(n=29) \\
\text { COPD }(n=33) \\
\text { Bronchiectasis }(n=13) \\
\text { Miscellaneous }(n=8)\end{array}$ & $\begin{array}{lr}49.2 & (12 \cdot 2) \\
51 & (10 \cdot 6) \\
61 & (8 \cdot 4) \\
36 & (14 \cdot 4) \\
57 \cdot 4 & (8 \cdot 4) \\
41 \quad(14 \cdot 4) \\
36 & (9 \cdot 9)\end{array}$ & $\begin{array}{l}6 \cdot 6(1 \cdot 6) \\
7 \cdot 1(1 \cdot 4) \\
6 \cdot 0(1 \cdot 2) \\
7 \cdot 5(1 \cdot 8) \\
6 \cdot 1(0 \cdot 8) \\
5 \cdot 6(1 \cdot 7) \\
7 \cdot 1(2 \cdot 0)\end{array}$ & $\begin{array}{l}8 \cdot 1(1 \cdot 4) \\
7 \cdot 9(1 \cdot 0) \\
8 \cdot 4(1 \cdot 5) \\
8 \cdot 4(1 \cdot 7) \\
8 \cdot 3(1 \cdot 8) \\
9 \cdot 1(1 \cdot 7) \\
8 \cdot 6(1 \cdot 0)\end{array}$ & $\begin{array}{ll}0.83 & (0.4) \\
1.1 & (0.4) \\
1.2 & (0.6) \\
1.3 & (0.7) \\
1.6 & (0.7) \\
1.0 & (0.5) \\
1.7 & (1.5)\end{array}$ & $\begin{array}{l}0.64(0.2) \\
0 \cdot 80(0 \cdot 2) \\
0 \cdot 80(0 \cdot 3) \\
0.98(0 \cdot 7) \\
0.58(0 \cdot 3) \\
0.48(0 \cdot 16) \\
1.6(1 \cdot 3)\end{array}$ \\
\hline
\end{tabular}

$\mathrm{PaO}_{2}, \mathrm{PaCO}_{2}$, and spirometric measurements available in 170 patients (arterial blood gas data are not included where measurements were made with the patient breathing supplemental oxygen).

failure which was unresponsive to standard measures, including controlled oxygen therapy. Nocturnal hypoventilation was demonstrated by overnight monitoring of arterial oxygen saturation and transcutaneous carbon dioxide tension. One hundred and thirty eight patients were treated electively with NIPPV after a progressive deterioration in symptoms and arterial blood gas tensions, and 42 received treatment following an acute hypercapnic exacerbation or were weaned from conventional ventilation using NIPPV. Among the group treated electively 15 patients were transferred from negative pressure ventilation (10 cuirass, three pneumojacket, two portable iron lung) when NIPPV became available at this institution in 1987. NIPPV was used as a "bridge" to transplantation ${ }^{9}$ in six subjects in the acute group. At the start of NIPPV all patients had normal or near normal bulbar function, and those receiving NIPPV electively were able to breathe spontaneously for at least 12 hours/day. Patients were recruited over a five year period from 1987-92.

VENTILATORY EQUIPMENT AND MONITORING

One hundred and seventy patients used volume preset ventilators (BromptonPAC, Pneupac Ltd; PLV 100, Lifecare; Monnal D, Deva Medical), and 10 used pressure preset equipment (BiPAP, Respironics Inc). All ventilators were operated in assist/control mode. Patients used

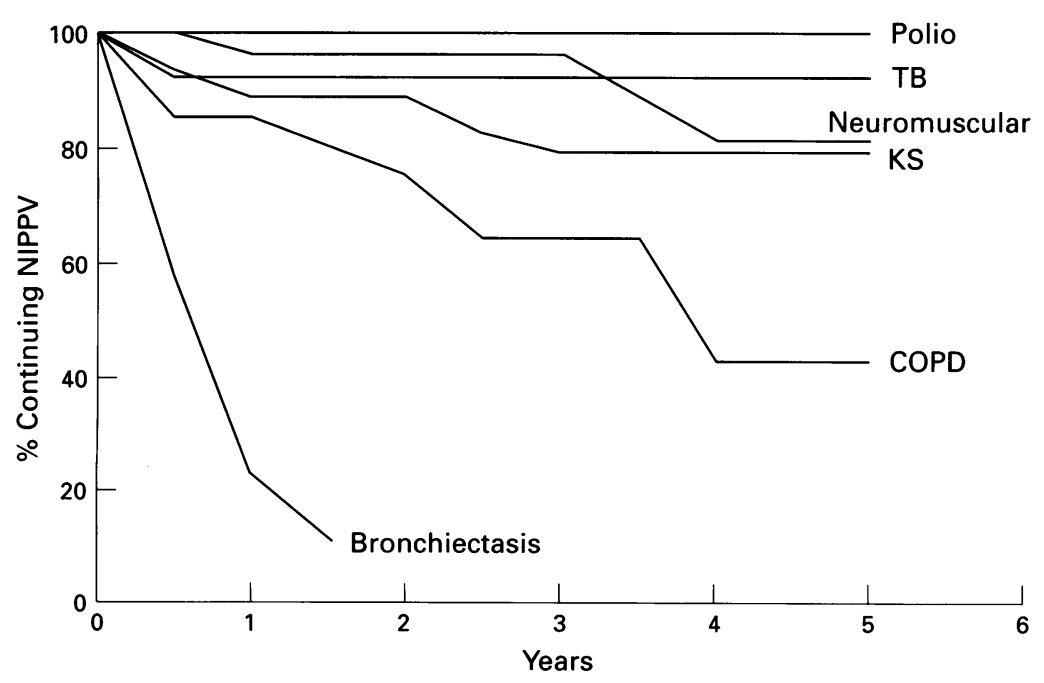

Figure 1 Probability of continuing nasal intermittent positive pressure ventilation (NIPPV) in different diagnostic groups. $K S=$ kyphoscoliosis; polio=poliomyelitis; $C O P D=$ chronic obstructive pulmonary disease; $T B=$ tuberculosis. commercial silicone nasal masks (Respironics Inc or Rescare Ltd).

Initial ventilator settings were determined by overnight monitoring of arterial oxygen saturation and transcutaneous carbon dioxide tension, and subsequently modified as necessary according to clinical course. Supplemental oxygen was entrained into the nasal mask at $1-21 / \mathrm{min}$ in individuals in whom arterial $\mathrm{SaO}_{2}$ remained below $90 \%$ for most of the night when they were ventilated with air. Each patient was instructed to use NIPPV during sleep. Humidification using a heat and moisture exchanger (Portex Thermovent) was added intermittently in 10 patients, predominantly those with bronchiectasis.

After starting NIPPV as inpatients, patients were initially reviewed as outpatients every $2-3$ months and subsequently at 6-12 month intervals. Arterial blood gas tensions and spirometric parameters were assessed at each outpatient attendance. All measurements of arterial blood gas tensions were made with the patient breathing air spontaneously during the day.

\section{QUALITY OF LIFE}

Health status was assessed on one occasion in a cross section of all patients currently using NIPPV in 1993. The SF-36 postal questionnaire was sent to 116 patients. Each received one follow up telephone call. The SF36 measure of health status assesses physical function, role limitation caused by physical or mental problems, social function, mental health, energy and vitality, pain and health perception. ${ }^{10}$ Additional questions were included on sleep quality and the side effects of NIPPV. The questionnaire was completed anonymously and coded by diagnostic group. Data from the SF-36 questionnaire were compared with UK population norms of similar age derived from general practice, ${ }^{11}$ and with a US study of outpatients with chronic medical conditions (diabetes, hypertension, recent myocardial infarction, cardiac failure). ${ }^{12}$

\section{COMPLIANCE}

Compliance with NIPPV was monitored in 43 randomly selected patients using volume preset ventilators by means of a hidden clock. The timing mechanism was activated only when the ventilator compressor was operating, and therefore measured hours of ventilator function rather than electrical run time. 
Table 2 Duration of nasal intermittent positive pressure ventilation (NIPPV) and reasons for withdrawal

\begin{tabular}{lll}
\hline & $\begin{array}{l}\text { Median (range) duration } \\
\text { of NIPPV (years) }\end{array}$ & Reasons for withdrawal \\
\hline Early onset scoliosis & $3 \cdot 2(0 \cdot 1-6 \cdot 9)$ & $\begin{array}{l}\text { Seven died (5 respiratory failure, 1 carcinoma breast, } \\
\text { 1 carcinoma ovary). One discontinued - improved }\end{array}$ \\
Previous polio & $4 \cdot 3(0 \cdot 6-6 \cdot 4)$ & $\begin{array}{l}\text { No withdrawals } \\
\text { One died (leukaemia) }\end{array}$ \\
Previous tuberculosis & $2 \cdot 1(0 \cdot 1-7)$ & $\begin{array}{l}\text { Four died (respiratory failure due to progression of underlying } \\
\text { disorder) }\end{array}$ \\
Neuromuscular disorders & $2 \cdot 8(0 \cdot 3-5 \cdot 9)$ & $\begin{array}{l}\text { Six died (respiratory failure). Five withdrawn (poor tolerance } \\
\text { NIPPV) }\end{array}$ \\
COPD & $1 \cdot 6(0 \cdot 1-6 \cdot 3)$ & $\begin{array}{l}\text { Seven died (respiratory failure). Two withdrawn (heart/lung } \\
\text { transplantation) } \\
\text { One died (respiratory failure) }\end{array}$ \\
Bronchiectasis & $0 \cdot 7(0 \cdot 1-2 \cdot 3)$ &
\end{tabular}

\section{STATISTICAL ANALYSIS}

The Kaplan-Meir technique was used to plot actuarial curves for the probability of continuing NIPPV. Arterial blood gas tensions and spirometric values before and after initiation of elective NIPPV in the groups with restrictive disorders and COPD were compared using Student's $t$ test. Patients beginning NIPPV as an acute measure, during weaning, or when bridging to transplantation were excluded from this analysis as blood gas tensions were unstable at the start of treatment. Responses to the SF36 questionnaire were examined by diagnostic group using ANOVA (Minitab Inc).

\section{Results}

CONTINUATION OF NIPPV (fig 1)

The five year actuarial probability of continuing NIPPV (mean, 95\% confidence interval) for early onset scoliosis was $79 \%$ (66 to 92), after poliomyelitis was $100 \%$, for previous tuberculosis $94 \%$ (83 to 100 ), neuromuscular disease $81 \%$ (61 to 100 ), COPD $43 \%$ (6 to $80 \%$ ). In the bronchiectasis group seven patients died after less than two years of treatment. Overall 26 of 180 patients died ( 23 respiratory failure, three unrelated disease), NIPPV was withdrawn in six (five poor tolerance, one improved), and two bronchiectatic patients received heart-lung transplants. Median duration of NIPPV and the reasons for withdrawal from therapy in each diagnostic group are given

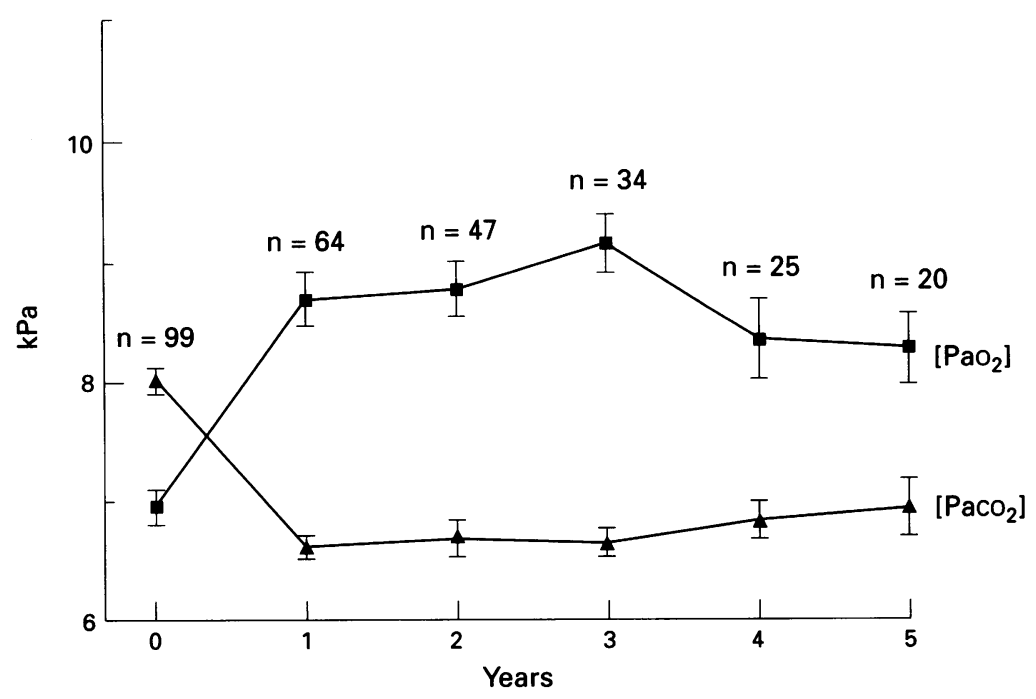

Figure 2 Mean (SE) arterial blood gas tensions over five years in patients with restrictive disorders who started nasal intermittent positive pressure ventilation for elective reasons. in table 2. All patients transferred from negative pressure ventilation to NIPPV expressed a preference to continue with NIPPV long term.

Mean (SD) NIPPV use per 24 hours was $7 \cdot 88(2 \cdot 1)$ hours with 16 of 43 patients using it for short periods in the day as well as during sleep at night. Supplemental oxygen therapy was used in $8.5 \%$ of patients with idiopathic scoliosis, $3.3 \%$ of post poliomyelitis patients, $30 \%$ of the previous tuberculosis group, $48 \%$ of patients with COPD, and in all patients with bronchiectasis.

ARTERIAL BLOOD GAS TENSIONS AND SPIROMETRIC VALUES

Arterial blood gas tensions improved in all patient groups. One hundred and eight patients with extrapulmonary restrictive disorders and 30 patients with COPD received NIPPV electively. Arterial blood gas data at the start of NIPPV were available in 99 of the 108 patients with restrictive disorders and in all 30 patients with COPD. After one year of elective NIPPV mean (SD) $\mathrm{PaO}_{2}$ compared with initial values increased by $1.8(1.9) \mathrm{kPa}(\mathrm{p}<0.0001)$ and $\mathrm{PaCO}_{2}$ fell by $1.4(1.3) \mathrm{kPa}(\mathrm{p}<0.0001)$ in patients with extrapulmonary restrictive disorders (idiopathic scoliosis, neuromuscular disease including poliomyelitis, and post tuberculous disease). Mean (SD) $\mathrm{PaO}_{2}$ rose by $0.8(1.0) \mathrm{kPa}(\mathrm{p}<0.01)$ and $\mathrm{PaCO}_{2}$ decreased by $0.9(0.8) \mathrm{kPa}(\mathrm{p}<0.001)$ in the group with 은 COPD. The trends in arterial blood gas ten- $\frac{7}{0}$ sions over five years of NIPPV in the group with extrapulmonary restriction are shown in $N$ fig 2 . In the subgroup of patients transferred $N$ from negative pressure ventilation to NIPPV N the best levels of arterial blood gas tensions achieved during the period of negative pressure ventilation were $\mathrm{PaO}_{2} 7.5(1 \cdot 2) \mathrm{kPa}, \mathrm{PaCO}_{2}$ $7 \cdot 1(1 \cdot 2) \mathrm{kPa}$. Values for this group improved significantly after using NIPPV for an average 0 of $38(17 \cdot 7)$ months to $\mathrm{PaO}_{2} 9.6(1.4) \mathrm{kPa}$ $(\mathrm{p}<0.001), \mathrm{PaCO}_{2} 6.3(0.7) \mathrm{kPa}(\mathrm{p}<0.005)$.

FVC and $\mathrm{FEV}_{1}$ did not change significantly $\stackrel{\mathbb{D}}{\varrho}$ over time in any patient group.

\section{HEALTH STATUS}

The response rate to the SF-36 questionnaire was $90.5 \%$ (105 of 116). The mean (SD) age of the respondents was $54.2(13.5)$ years; duration of NIPPV use in these patients ranged from six months to seven years. Results are given in fig 3 (where a score of $100 \%$ represents normal function or no pain, and $0 \%$ indicates 


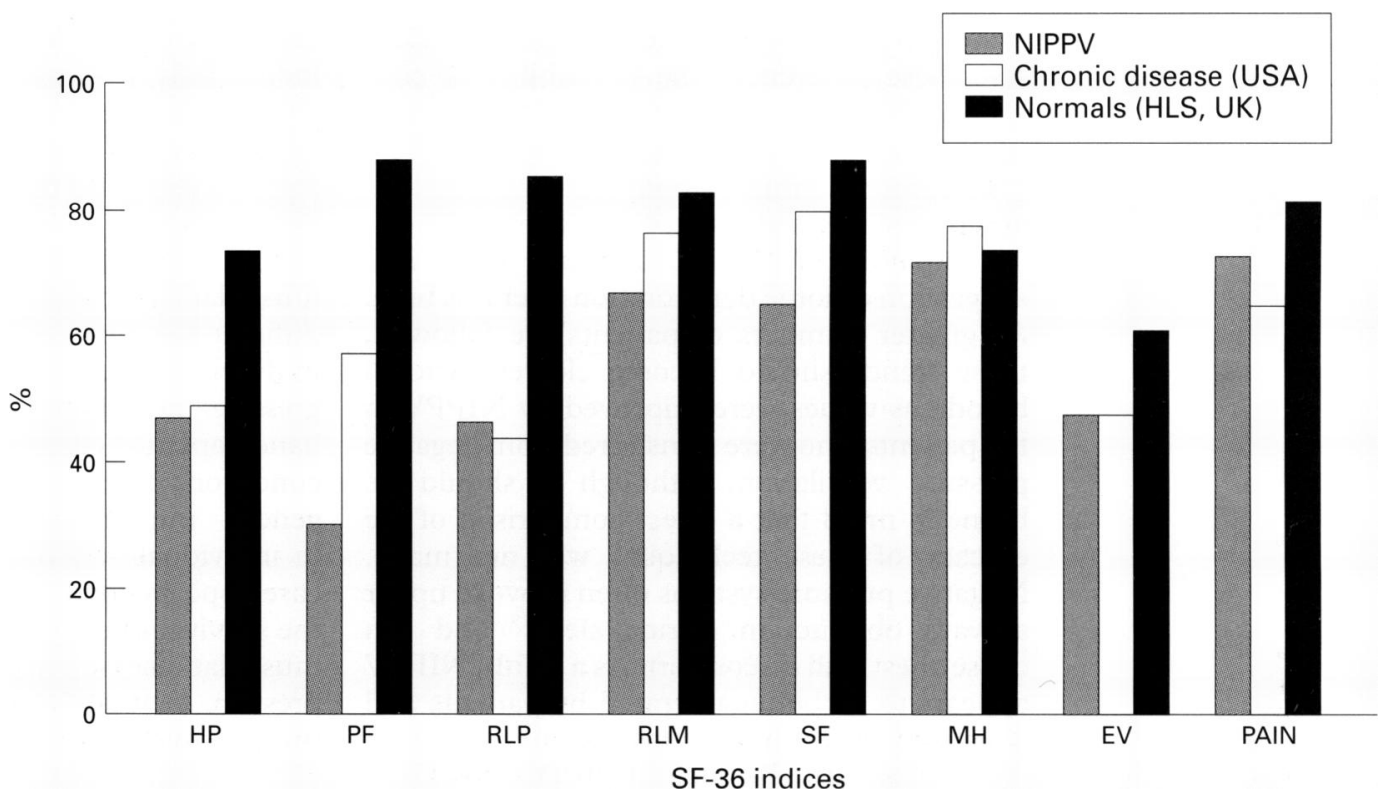

Figure 3 Health status measured by SF-36 questionnaire in patients receiving nasal intermittent positive pressure ventilation (NIPPV) in a USA group with chronic diseases and in UK normal subjects (Healthy Life Survey (HLS), Oxford). $H P=$ general health perceptions; $P F=$ physical functioning; $R L P=$ role limitations due to physical problems; $R L M=$ role limitations due to emotional problems; $S F=$ social functioning; $M H=$ general mental health; $E V=$ energy/ vitality.

lowest possible value or maximal pain). Physical function was significantly higher in groups with idiopathic scoliosis, after poliomyelitis, and previous tuberculosis compared with the COPD group. Patients with neuromuscular disorders and COPD had a similar level of physical function, but role limitation due to physical factors was greater in the COPD group ( $65 \%$ versus $18.7 \%, \mathrm{p}<0.01)$. Health status outcome in the patients receiving NIPPV was comparable to the group with chronic disorders reported from the USA. Although physical function was reduced compared with the UK population norms, mental health and energy and vitality were similar.

Sleep quality was rated poor in $5 \%$ of patients, average in $67 \%$, and very good in $21 \%$. There was no correlation between hours of ventilator use and sleep quality. The commonest reported disadvantages of NIPPV were inconvenience (20 patients), nasal/mask problems (10), gastric distension (three), and noise (three).

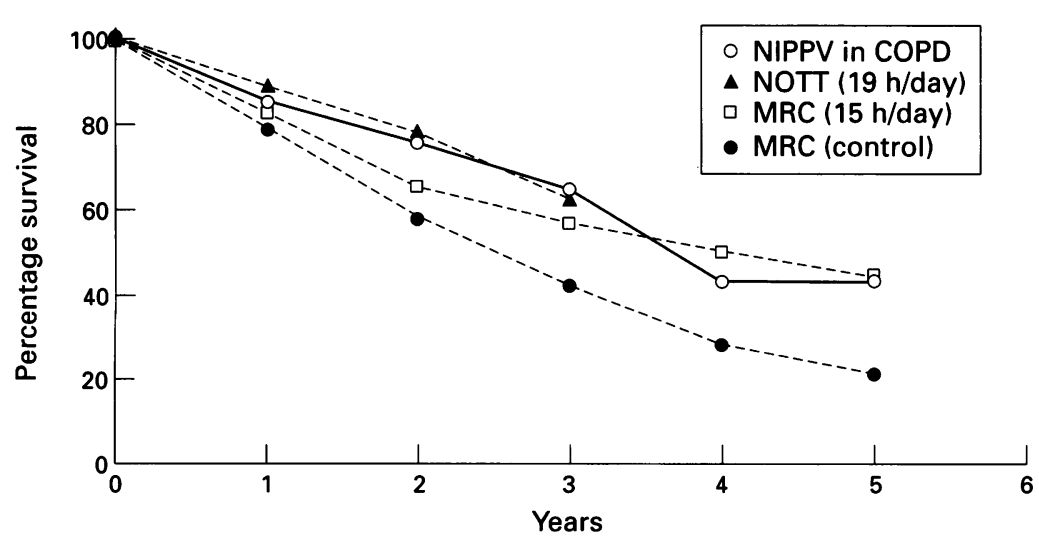

Figure 4 Percentage survival in patients with COPD receiving NIPPV compared with data from NOTT trial (oxygen 19 hours/day), MRC trial (oxygen 15 hours/day) and control group from MRC trial.

\section{Discussion}

As nocturnal hypoventilation is the common denominator in patients with chest wall disorders, neuromuscular conditions, and chronic obstructive lung disease who progress to cor pulmonale and premature death, it is logical to examine the effects of long term correction of nocturnal arterial blood gas tensions with NIPPV on outcome. There have been no long term controlled studies of domiciliary NIPPV in chronic ventilatory failure. In patients with hypercapnic respiratory failure secondary to restrictive chest wall disorders such as idiopathic scoliosis, previous poliomyelitis and tuberculosis, premature death ${ }^{1314}$ is an inevitable consequence if chronic hypoxaemia and hypercapnia are not reversed. The five year probability of continuing NIPPV is a close approximation to five year survival in these groups, as death was the principal cause of withdrawal from the study. Furthermore, deaths in these subgroups were largely due to concurrent disease (malignancy) or progression of pulmonary hypertension in patients who presented late for NIPPV. With a five year survival figure of around $80 \%$ or higher, and evidence that withdrawal of NIPPV results in a recurrence of nocturnal hypoventilation, ${ }^{15}$ a randomised controlled study would appear unethical in patients with idiopathic scoliosis, previous poliomyelitis, and old tuberculous lung disease. ${ }^{16}$ Leger $e t ~ a l^{7}$ have reported data from an uncontrolled French multicentre study of NIPPV in groups with scoliosis, previous tuberculosis, Duchenne muscular dystrophy, COPD, and bronchiectasis. Although similar ventilatory methods were used, the French patients differ from the population in the current study in that they tended to have a higher $\mathrm{PO}_{2}$ and lower $\mathrm{PCO}_{2}$ on initiation of NIPPV, at least $60 \%$ of the French patients with scoliosis received supplemental oxygen therapy, and the 
follow up period was shorter (36 months). Despite these differences the probability of continuing NIPPV at 36 months in the French study is similar to the results presented here.

Control of diurnal arterial blood gas tensions was maintained over four years following elective initiation of NIPPV, although there is a suggestion of some deterioration after this time. As greater numbers of patients are followed, these trends should become clearer. Arterial blood gas values were improved by NIPPV in the patients who were transferred from negative pressure ventilation, although it should be borne in mind that a direct comparison of the efficacy of these techniques was not made. Negative pressure systems often provoke upper airways obstruction during sleep ${ }^{17}$ and can cause chest wall discomfort. As a result, NIPPV appears to be better tolerated by patients and is usually easier to institute.

Patients with end stage COPD differ from those with extrapulmonary restrictive disorders as, in addition to alveolar hypoventilation, gas exchange is also severely impaired. Long term oxygen therapy (LTOT) is the mainstay of treatment of respiratory failure in COPD, and has been shown to produce improved survival in those using oxygen for 15 or more hours a day. ${ }^{18}$ However, there are problems associated with LTOT, including the fact that no consistent increase in quality of life has been demonstrated in recipients, compliance with therapy may be poor, and a small proportion of patients with COPD are unable to tolerate controlled oxygen therapy due to progressive and/or symptomatic hypercapnia. A controlled trial of domiciliary negative pressure ventilation used with the aim of "resting" the respiratory muscles, ${ }^{19}$ and a crossover study of pressure support ventilation ${ }^{20}$ in end stage COPD, both produced no overall benefit in terms of symptom control or physiological measures. By contrast, Elliott et $a l^{21}$ demonstrated an improvement in nocturnal and diurnal arterial blood gas tensions in a pilot study of domiciliary NIPPV over one year in hypercapnic COPD patients. This beneficial effect was attributed to an increase in ventilatory drive and reduction in ventilatory load. No change in respiratory muscle function was seen. ${ }^{22}$ Severely hypercapnic patients and those with symptomatic sleep disturbance showed the most improvement in nocturnal and diurnal arterial blood gas tensions. Individuals with end stage emphysema were unlikely to derive benefit. The patients with COPD included in the present study represent the most severe end of the spectrum of respiratory failure in COPD (mean $\mathrm{PCO}_{2}$ on entry $8.3 \mathrm{kPa}$ ) and most were deteriorating despite long term oxygen therapy. Hypercapnic patients have a poor prognosis. ${ }^{18}$ Although withdrawal from NIPPV due to intolerance was higher in the patients with COPD than in the other groups, the probability of continuing NIPPV at five years of $43 \%$ is comparable to the survival results of long term oxygen therapy in previous studies (fig 4). ${ }^{182324}$ Such retrospective comparisons with unmatched populations are unsatisfactory, but the results of this study suggest that long term domiciliary NIPPV is a practical proposition in carefully selected patients with end stage COPD who are deteriorating despite long term oxygen therapy. However, self-reported health status is less good than in those with restrictive disorders.

The heterogenous nature of the neuromuscular and miscellaneous groups makes it difficult to draw conclusions on the outcome in different diseases, including those with progressive neuromuscular disorders, multiple handicaps (for example, spina bifida) and rare conditions (for example, scleroderma, osteogenesis imperfecta). However, the outlook in individuals with stable neuromuscular disease appears good. Sawicka et $a l^{25}$ showed that the survival in patients with progressive neuromuscular disease receiving domiciliary negative pressure ventilation was largely related to the progress of the underlying condition, and this is likely to remain the case regardless of ventilatory technique. Quality of life or health status is the most appropriate outcome measure in these patients. In this study no patient elected to transfer from NIPPV to ventilation via a tracheostomy, although only one individual (with motor neurone disease) developed severe bulbar problems.

In the bronchiectasis group the probability of continuing NIPPV after two years was less than $20 \%$, and most patients became increasingly more ventilator-dependent with time. All were extremely unwell at the start of NIPPV, having been referred for consideration for heart-lung transplantation. Only two received transplants - in the remainder either organs were unavailable or patients were not eligible for the transplant programme because of comorbidity. The response to NIPPV in this group is disappointing and worse than has been shown in a previous study. ${ }^{7}$ However, our patients had more severe hypoxaemia and hypercapnia at the start of NIPPV suggesting that ventilation was introduced later in the natural history of the disease.

Several conclusions can be drawn from this open study. Domiciliary NIPPV is generally well tolerated and associated with excellent five year survival in patients with extrapulmonary restrictive disorders. The SF-36 was administered on one occasion after a variable period of NIPPV and therefore cannot give an indication of the impact of the treatment, merely a single view of health status at the time of measurement. Despite this major limitation it can be seen that, although physical function is reduced compared with normal subjects, levels of social function and self-reported health status contradict the commonly held belief that domiciliary ventilator-dependent patients experience a severely limited lifestyle and poor quality of life. The outcome in patients with end stage, hypercapnic COPD who fail to tolerate LTOT is encouraging, and suggests that controlled studies are warranted. A European trial comparing LTOT and an LTOT/NIPPV combination is in progress. For groups with progressive disorders NIPPV can produce symptom relief and a satisfactory quality of life. There are important ethical issues involved in 
carrying out controlled trials in these patients. In the first instance more data are required on the outcome of NIPPV in progressive neuromuscular disease, and in other conditions which affect relatively small numbers of patients. This should be facilitated by a national register of home ventilator patients which has recently been established by the British Thoracic Society.

We are indebted to Dr M A Branthwaite who established the Respiratory Support Service at the Royal Brompton Hospital, and to Ms Nikki Potter, Senior Respiratory Support technician, for data collection and technical skills.

1 Muir J-F. Home mechanical ventilation. Thorax 1993;48: 1264-73.

2 Brochard L, Isabey D, Piquet J, Piedade A, Mancebo J, Messadi A-A, et al. Reversal of acute exacerbations of chronic obstructive lung disease by inspiratory assistance with a face mask. $N$ Engl 7 Med 1990;323:1523-30.

3 Elliott MW, Steven MH, Phillips GD, Branthwaite MA. Non-invasive mechanical ventilation for acute respiratory Non-invasive mechanical ventilati
failure. $B M \mathcal{F}$ 1990;300:358-60.

4 Bott J, Carroll MP, Conway JH, Keilty SE, Ward EM, Brown AM, et al. Randomised controlled trial of nasal ventilation in acute ventilatory failure due to chronic obstructive airways disease. Lancet 1993;341:1555-7.

5 Meduri GU, Conoscenti CC, Menashe P, Nair S. Noninvasive face mask ventilation in patients with acute respiratory failure. Chest 1989;95:865-70.

6 Udwadia ZF, Santis GK, Steven MH, Simonds AK. Nasal ventilation to facilitate weaning in patients with chronic ventilation to facilitate weaning in patients with
respiratory insufficiency. Thorax 1992;47:715-8.

7 Leger P, Bedicam JM, Cornette A, Reybet-Degat O, Langevin $\mathrm{B}$, Polu JM, et al. Nasal intermittent positive pressure ventilation. Long term follow-up in patients with severe chronic respiratory insufficiency. Chest 1994;105:100-5.

8 Pehrsson K, Olofson J, Larsson S, Sullivan M. Quality of life in patients treated by home mechanical ventilation due to restrictive ventilatory disorders. Respir Med 1994; 88:21-6.

9 Hodson ME, Madden BP, Steven MH, Tsang VT, Yacoub MH. Non-invasive mechanical ventilation for cystic fibrosis patients - a potential bridge to transplantation. Eur rosis patients - a poten
Respir $₹$ 1991;4:524-7.

10 Ware JE. Measuring patients' views: the optimum outcome measure. SF-36: a valid, reliable assessment of health from a patient's point of view. $B M F$ 1993;306:1429-30.
11 Brazier JE, Harper R, Jones NMB, O'Cathain A, Thomas $\mathrm{KH}$, Usherwood $\mathrm{T}$, et al. Validating the SF-36 health survey questionnaire: new outcome measure for primary care. $B M F$ 1992;305:160-4.

12 McHorney CA, Ware JE, Raczek AE. The MOS 36-item short-form health survey (SF-36): II. psychometric and clinical tests of validity in measuring physical and mental health constructs. Med Care 1993;31:247-63.

13 Freyschuss V, Nilsonne U, Lundgren KD. Idiopathic scoliosis in old age. 1. Respiratory function. Arch Med Scand 1968;184:365.

14 Piper AJ, Sullivan CE. Sleep-disordered breathing in neuromuscular disease. In: Saunders NA, Sullivan CE, eds. Sleep and breathing. New York: Marcel Dekker, 1994 765-8.

15 Hill NS, Eveloff SE, Carlisle CC, Goff SG. Efficacy of nocturnal nasal ventilation in patients with restrictive thoracic disease. Am Rev Respir Dis 1992;145:365-71.

16 Hill N. Noninvasive ventilation. Does it work, for whom, and how? Am Rev Respir Dis 1993;147:1050-5.

17 Levy RD, Bradley TD, Newman SL, Macklem PT, Martin JG. Negative pressure ventilation. Effects on ventilation during sleep in normal subjects. Chest 1989;95:95-9.

18 Medical Research Council Working Party Report. Long term domiciliary oxygen therapy in chronic hypoxic cor pulmonale complicating chronic bronchitis and emphysema. Lancet 1981;i:681-5.

19 Shapiro SH, Ernst P, Gray-Donald K, Martin JG, WoodDauphinee $S$, Beaupre A, et al. Effect of negative pressure ventilation in severe chronic obstructive pulmonary disease. Lancet 1992;340:1425-9.

20 Strumpf DA, Millman RP, Carlisle CC, Gratton LM, Ryan $\mathrm{SM}$, Erickson AD, et al. Nocturnal positive-pressure ventilation via nasal mask in patients with severe chronic obstructive pulmonary disease. Am Rev Respir Dis 1991; 144:1234-9.

21 Elliott MW, Simonds AK, Carroll MP, Wedzicha JA, Branthwaite MA. Domiciliary nocturnal nasal intermittent positive pressur positive pressure ventilation in hypercapnic respiratory failure due to chronic obstructive lung disease: effects on

22 Elliott MW, Mulvey DA, Moxham J, Green M, Branthwaite MA. Domiciliary nocturnal nasal intermittent positive pressure ventilation in COPD: mechanisms underlying changes in arterial blood gas tensions. Eur Respir $\mathcal{F} 1991$ 4:1044-52.

23 Nocturnal Oxygen Therapy Trial Group. Continuous or nocturnal oxygen therapy in hypoxaemic chronic obstructive lung disease, a clinical trial. Ann Intern Med 1980; 93:391-8.

24 Cooper CB, Waterhouse J, Howard P. Twelve year clinica study of patients with hypoxic cor pulmonale given long study of patients with hypoxic cor pulmonale given long

25 Sawicka EH, Loh L, Branthwaite MA. Domiciliary ventilatory support; an analysis of outcome. Thorax 1988;43: 31-5. 